\title{
Development of a crop water use module for the WAS program to determine scheme-level irrigation demand
}

\author{
I. van der Stoep ${ }^{1} \&$ N. Benadé ${ }^{2}$ \\ ${ }^{I}$ Department of Civil and Biosystems Engineering, University of Pretoria, \\ South Africa \\ ${ }^{2} N B$ Systems cc, South Africa
}

\begin{abstract}
The water use sector in South Africa is currently implementing the National Water Act (Act 36 of 1998), which requires, amongst other things, improved planning of expected water demands. A need was identified for the development of a computer model that can assist Water User Associations (WUAs) to easily and effectively capture data for management and planning purposes. The existing Water Administration System (WAS) computer program was used and a new module developed to capture data and perform calculations so that irrigation demand can be determined for different time periods (daily, seasonally, annually, etc.) and management levels (field, farm, and scheme). The crop yield (ton/ha) can also be captured at the end of a growing season and used to calculate the total yield (ton) and the yield per unit of water $\left(\mathrm{g} / \mathrm{m}^{3}\right)$. A summary of water demand for a specified period can easily be generated per crop type, and all the crop water demand information can easily be linked to a geographic information system (GIS). The module was implemented at the Orange-Riet WUA where it is used to model irrigation demand for 16700 ha of mixed crops irrigated from river and canal distribution systems.
\end{abstract}

Keywords: irrigation planning, crop water requirements, WAS program, water conservation and demand management.

\section{Introduction}

South Africa is a semi-arid country where water is of critical strategic importance to all development, in any sector of the economy. Recognising the 
potential limiting effect that water could have on future economic expansion in this country, it is of utmost importance that this resource be optimally utilised to the benefit of all current and future users.

The National Water Act (Act 36 of 1998) (NWA) provides for water to be protected, utilised, developed, conserved, managed and controlled, in a sustainable and equitable manner (Department of Water Affairs and Forestry (DWAF) [1]).

The water use sector in South Africa is currently implementing the NWA, part of which is the Water Conservation and Water Demand Management (WCWDM) strategy. In the agricultural water sector, the WCWDM strategy requires each Water User Association (WUA) to develop a Water Management Plan (WMP) that, amongst other things, reflects current and expected water demand (DWAF [2]). A need was identified for the development of a computer model that can assist WUAs to perform this task easily and effectively for management and planning purposes.

To address this need, the existing Water Administration System (WAS) computer program (Benadé et al [3]) was used and a new module developed to capture data and perform calculations so that irrigation demand can be determined for different time periods (daily, seasonally, annually, etc.) and management levels (field, farm, and scheme).

The main function of the Crop Water Use module is to calculate the volume of water required between two specified dates for all the planted crops on a scheme based on the planting date, irrigated area and the crop water demand curve. The crop yield (ton/ha) can be captured at the end of a growing season which is used to calculate the total yield (ton) and the yield in $\left(\mathrm{g} / \mathrm{m}^{3}\right)$. A summary of water demand for a specified period can easily be generated per crop type, and all the crop water demand information can easily be linked to a geographic information system (GIS).

The paper addresses the development of the Crop Water Use module as well as its implementation at the Orange-Riet WUA where it is used to model irrigation demand for 16700 ha of mixed crops irrigated from river and canal distribution systems.

\section{Module development and functions}

One of the key components of the agricultural WMP is the calculation of benchmarks according to which the WUA's performance can be assessed. The primary benchmarks for irrigation water use are firstly the crop water requirement of a specific crop $\left(\mathrm{ET}_{\text {crop }}\right)$ in a specific area at a specific time of year. $\mathrm{ET}_{\text {crop }}$ does not take irrigation efficiency factors into account. Secondly, the $\mathrm{ET}_{\text {crop }}$ benchmark can be used to calculate the gross irrigation water requirements (GIR) for a specific crop in a specific area and at a specific time of year by adjusting the crop water requirement for appropriate irrigation efficiency factors such as leaching requirements, irrigation application efficiency, effective rainfall and reasonable transmission losses (mainly evaporation). These benchmarks can, in turn, be used to calculate the expected irrigation water 
requirements for the WUA as a whole by taking into account actual irrigated areas for each type of crop (DWAF [1]).

Research on crop water use and irrigation requirements for a wide range of commercial crops in different climatic regions and on different soil types has been ongoing in South Africa for over 25 years. The standard approach recommended in the WCWDM strategy is based on the following two components:

- The Penman-Monteith method of estimating reference evapotranspiration $\left(\mathrm{ET}_{\mathrm{o}}\right)$ in any given zone and

- The FAO method of linking reference evapotranspiration to any given crop by way of a standard crop factor $\left(\mathrm{K}_{\mathrm{c}}\right)$ for any given period during the growing season of the crop. This method is described in the FAO Irrigation and Drainage Paper No. 56 (FAO 1998).

It can be expressed as shown in eqn (1):

$$
E T_{\text {crop }}=E T_{0} \times K_{C}
$$

In contrast to the crop factors used with A-pan, reference evaporation, $\mathrm{K}_{\mathrm{c}}$ can be adjusted consistently and with confidence to accommodate differences in climatic zone and farming practice. Because the short grass reference evapotranspiration already accounts for many of the implications of differences in climate, it is often possible to use a single set of crop coefficients for different climatic zones. The $\mathrm{ET}_{0}-\mathrm{K}_{\mathrm{c}}$ approach has become a widely accepted international standard and has therefore been accepted by DWAF as a basis for establishing crop water requirement and irrigation requirement benchmarks. The WAS program is structured in accordance with these principles

The program allows the user considerable freedom to develop crop coefficients that are well suited to specific cropping circumstances. Because the $\mathrm{ET}_{0}-\mathrm{K}_{\mathrm{c}}$ approach has been so well accepted internationally, a wealth of information is available, especially through another South African model, SAPWAT, which is recognised as the irrigation planning tool for SA by DWAF (Crosby \& Crosby [4]).

The crop water use module of the WAS program can be used to calculate the total water demand value for an irrigation scheme consisting of different sized fields where various crops are planted as daily, weekly, monthly, annually or any other periodic values. These calculations need to be viewed as guidelines for irrigation water requirements and may need to be tempered by local experience.

\subsection{Inputs required}

The program requires three types of inputs in order to perform the most basic calculations: planted area information, crop types and water use values for the crop types.

\subsubsection{Lands}

The planted area information is captured as irrigated land areas (in hectares) per water user. A Land ID must be specified and there is no limit to the number of lands that can be captured per water user (Figure 1). The irrigation system and scheduling method can also be specified. This information can be used with a geographic information system (GIS) to link different land areas to a map. 


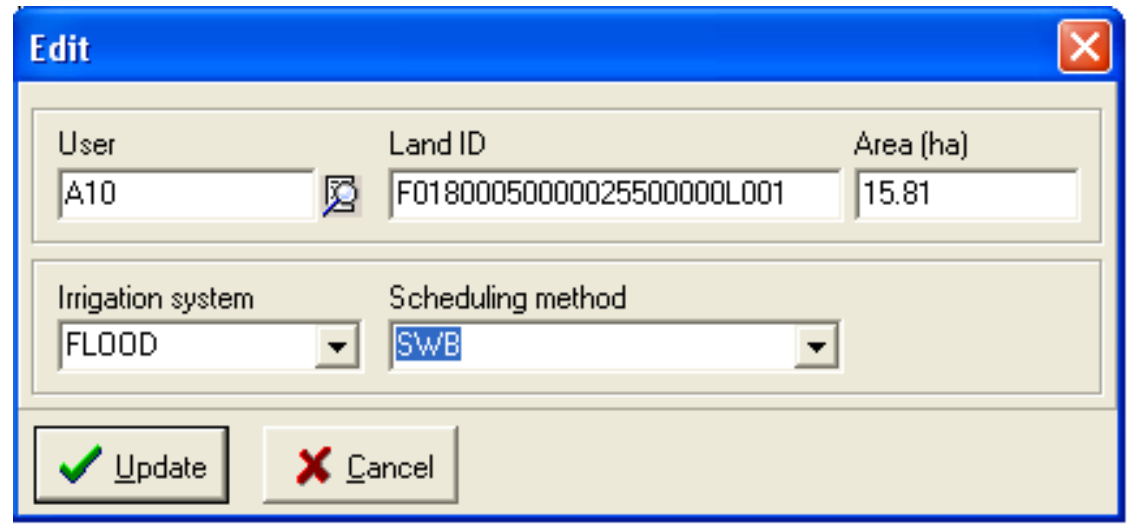

Figure 1: $\quad$ Form for capturing planted areas information.

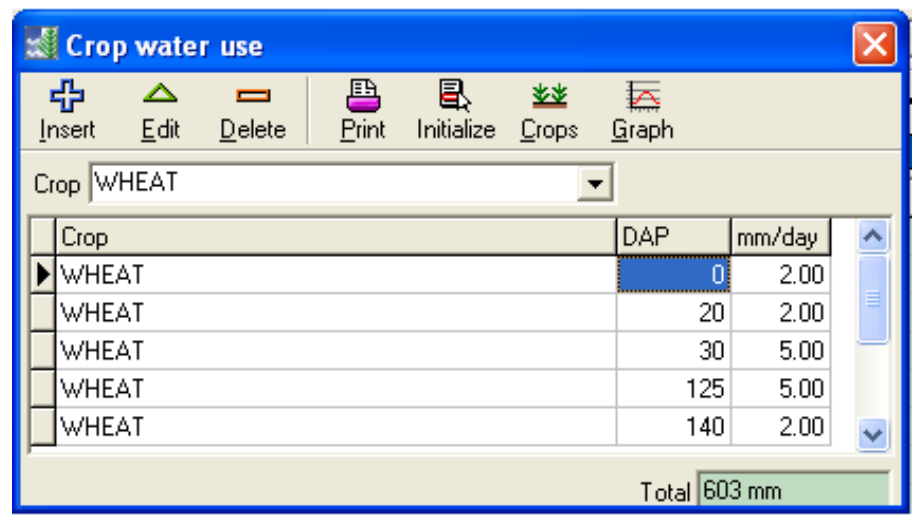

Figure 2: Crop water use data capturing form.

The total land area captured under the Lands form is used to verify the total area on the Crops \& planted areas form where a land may be planted with more than one crop on different areas. The difference between the land area and the planted area will be displayed in red at the bottom of the Crop water use and planted areas form.

\subsubsection{Crops}

All the different crops planted on a scheme must be captured on the crops lookup form to make it available in the dropdown list on the capturing forms.

The Crops speed button is used to maintain the crop lookup list. For each crop, a crop ID nr and a description have to be entered. The description may refer to a specific crop variety or planting season (e.g. early or late).

\subsubsection{Water use}

The Water Use speed button is used to capture the crop water use information per crop type (Figure 2). The information needed are the days after planting 
(DAP) and the corresponding water use per day (mm/day). There is no limitation on the number of points that can be captured to describe the crop water use graph. The crop water use graph shown in Figure 3 can be generated from the crop water use data.

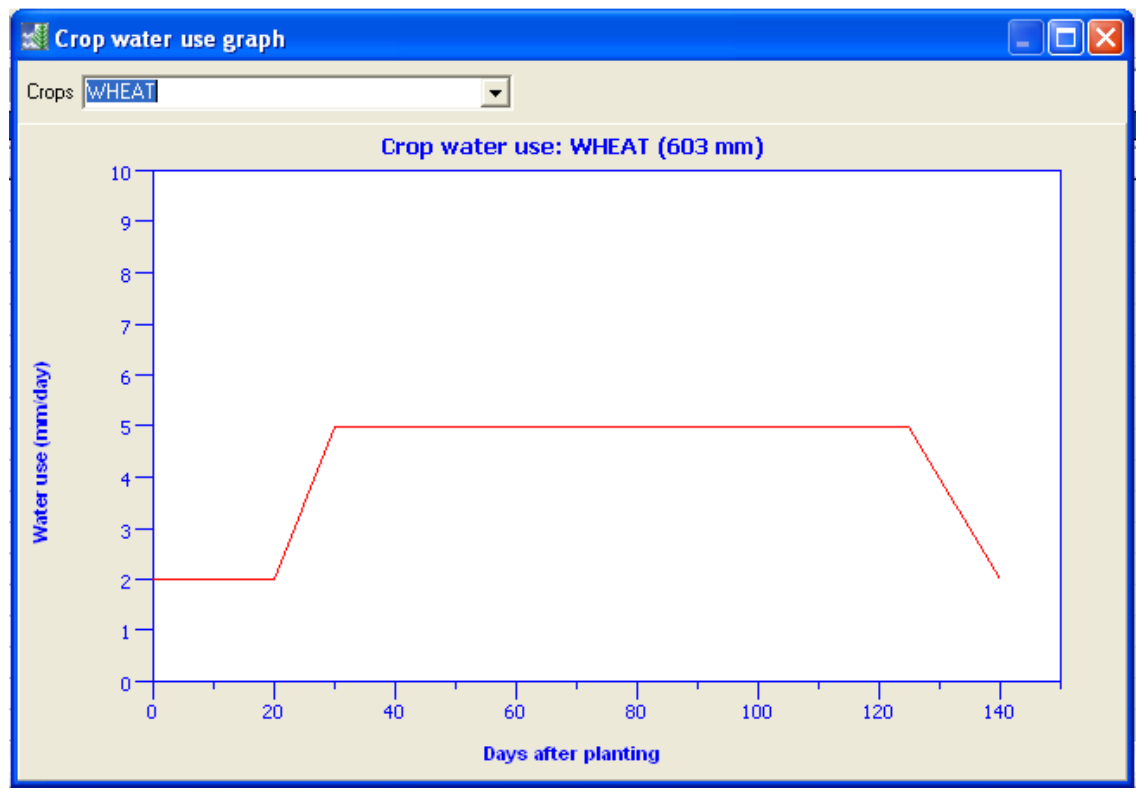

Figure 3: $\quad$ Typical crop water use graph.

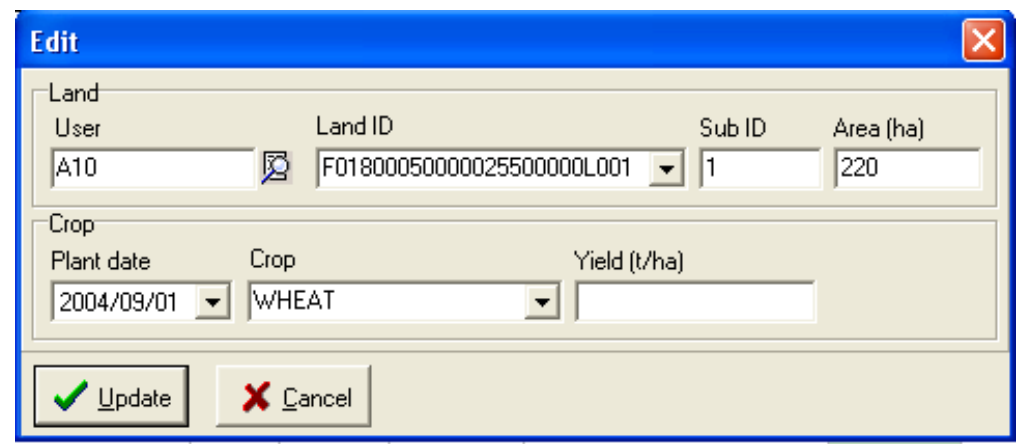

Figure 4: $\quad$ Linking the planted area to a specific crop.

\subsubsection{Other inputs}

The last step is to link all the planted areas to a specific crop and indicate the planting date for the specific field. This is done by editing any of the entries on the planted areas list as shown in Figure 4. The expected (for planning) or actual (for reporting) yield is an optional entry on the data capturing form. 


\subsection{Functions}

Once all the required data have been captured, the crop water use module can be used to display, calculate and summarise water use reports per crop for different time periods and /or specific users using the links at the top of the window (Figure 5).

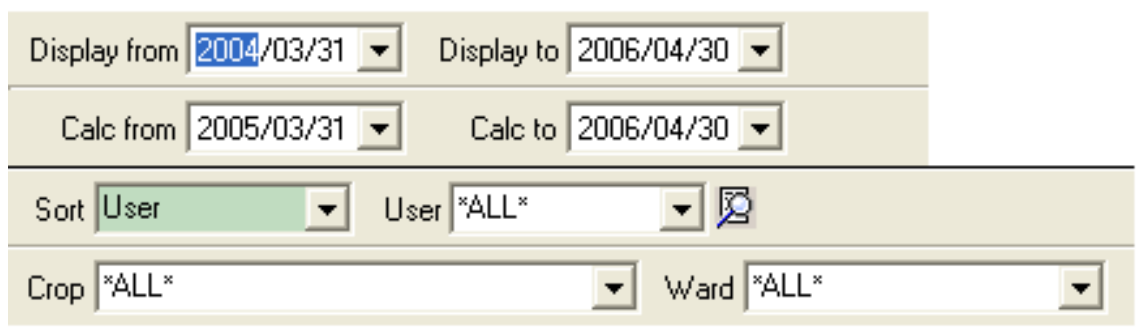

Figure 5: Display options.

\subsubsection{Display options}

The "Display from" and "Display to" date dropdown boxes are used to specify the period in which all the crops that are planted must be displayed, while the "Calc from" and "Calc to" date dropdown boxes are used to specify the period which is used to calculate the crop water use volumes.

The "User" dropdown box is used to filter the crop water use records according to a specified user. This option will be relevant for cases where a user has more then one Land ID.

The "Crop" dropdown box is used to filter the crop water use records according to the selected crop, and the "Ward" dropdown box is used to filter the crop water use records according to the selected water ward.

\subsubsection{Calculating results}

The "Calc" speed button is used to calculate the crop water use volume $\left(\mathrm{m}^{3}\right)$ for the options decided on by the user and it opens a dropdown menu with two further options. The "Current volume" option is used to calculate the crop water use for the current record shown and the "All volumes" option will calculate it for all the records in the database. The total volume of water use during the specified period and the total planted area are displayed in the bottom right corner of the screen (see Figure 4).

\subsubsection{Output options}

The "Summary" speed button generates a Crops \& planted areas summary report per crop that can be printed. Information regarding planted areas, volume of water, average irrigation requirement per season, yields, and yield per water unit is presented per crop, for the information that had been entered. 


\section{Results from the Orange-Riet case study}

The crop water use module was originally developed specifically for the OrangeRiet WUA (ORWUA) in South Africa. The ORWUA is located along the Orange and Riet Rivers in the north-western region of the country, which has a semi-arid climate with mean annual rainfall typically less than $400 \mathrm{~mm}$. Irrigated agriculture has been practised in the area since 1945.

An area of approximately 16780 ha is dependent on irrigation water from the Orange-Riet Canal, which is a transfer scheme between the two rivers, and includes the Riet River settlement, development along the Orange-Riet Canal, Scholtzburg and Ritchie Irrigation Boards and the lower Riet River Irrigation Board. The first $74 \mathrm{~km}$ of the canal has a capacity of $16 \mathrm{~m}^{3} / \mathrm{s}$ while the last $38 \mathrm{~km}$ has a capacity of $13 \mathrm{~m}^{3} / \mathrm{s}$. Water is pumped at the Scheiding Pumping Station at the terminal of the main canal to an elevation of $47 \mathrm{~m}$ above the river to the entrance of the Orange-Riet Canal.

Due to the harsh climate and the limited canal capacity, water use planning is an essential component of the ORWUA's water management system and water users are strongly encouraged not to plant larger areas than for which they have water rights. Supply and demand has to be carefully matched, especially during peak periods to ensure that all the water users receive their fair share and pumping costs are kept to a minimum. For these reasons the ORWUA was selected as one of three irrigation schemes in South Africa for which draft a WMP has been developed and is currently being implemented.

The crop water use module has been used at the ORWUA since 2002 to capture data, plan water requirements and compare theoretical water demand with actual use.

\subsection{Data inputs}

A wide range of crops are grown in the area. A summary of planted area data per crop type that have been captured over the last 4 years is shown in Table 1 . The ORWUA operates according to a water year that runs from 1 April to 31 March, with most of the rain event occurring between October and April and the peak irrigation demand periods occurring in November and February.

The table shows that the most important crops grown in the area are maize, wheat and lucerne (alfalfa). However, due to the poor maize prices in 2004 and 2005 , there has bee a sharp decline in maize planting, with farmers instead opting for crops such as pastures, sunflowers and peanuts as well as favouring wheat.

It is interesting to note that there has been a steady decrease in the total planted areas in the ORWUA since the 2003/2004 season. Tough economic conditions and other contributing factors such as new labour laws and crime in rural areas have resulted in farmers leaving the agricultural sector to pursue other business interests.

The benchmark water use values for the crops have been developed over a number of years by monitoring and recording irrigation applications for the 
various types of irrigation systems and scheduling approaches used by farmers in the area. The crop water use graphs entered in the crop water use module had to be developed so that the total seasonal water requirements as shown in the program matched the benchmark values.

Table 1: $\quad$ Planted area data for the ORWUA (2002-2006).

\begin{tabular}{|c|c|c|c|c|c|}
\hline & \multicolumn{4}{|c|}{$\begin{array}{c}\text { Planted areas per water year } \\
\text { (ha) }\end{array}$} & $\begin{array}{l}\text { Benchmark } \\
\left(\mathrm{m}^{3} / \mathrm{ha}\right)\end{array}$ \\
\hline Crop & $2002 / 03$ & $2003 / 04$ & $2004 / 05$ & $2005 / 06$ & \\
\hline Maize & 14036 & 12304 & 11979 & 5583 & 7820 \\
\hline Wheat & 8736 & 11623 & 9738 & 10132 & 6250 \\
\hline Lucerne & 2243 & 1846 & 2391 & 2852 & 12150 \\
\hline Potatoes & 366 & 566 & 518 & 567 & 6980 \\
\hline Pastures & 361 & 950 & 1595 & 2342 & 11800 \\
\hline Vineyards & 358 & 325 & 274 & 242 & 8650 \\
\hline Peanuts & 259 & 858 & 437 & 809 & 6800 \\
\hline Onions & 204 & 232 & 144 & 548 & 6660 \\
\hline Sunflowers & 196 & 564 & 548 & 869 & 5880 \\
\hline Vegetables & 196 & 150 & 48 & 508 & 5880 \\
\hline Dry beans & 143 & 337 & 108 & 331 & 4490 \\
\hline Pecan nuts & 78 & 84 & 60 & 70 & 9340 \\
\hline Cotton & 39 & 308 & 127 & 151 & 8300 \\
\hline Fruit trees & 37 & 21 & 23 & 17 & 9940 \\
\hline Olives & 16 & 49 & 32 & 35 & 4600 \\
\hline Soya beans & 0 & 116 & 22 & 123 & 4820 \\
\hline Totals & 27268 & 30333 & 28044 & 25179 & \\
\hline
\end{tabular}

\subsection{Results}

The results of the four year long data collection process is summarised in Figure 6. It shows the irrigation water demand, the bulk water supply and planted areas for the four water years.

The irrigation water demand values were obtained from the crop water use module output as calculated for the planted areas shown in Table 1. The bulk water supply values were obtained from records of the Scheiding Pumping Station that supplies water to the ORWUA.

The irrigation water demand values also reflect the changes in planted areas over the four years, with water demand peaking in 2003/2004. The average irrigation water demand per planted area was $6556 \mathrm{~m}^{3} /$ ha during the four years, and this can be seen as the net irrigation demand for the WUA. This value has increased continuously over the last three water years (from 6482 to 6722 $\mathrm{m}^{3} / \mathrm{ha}$ ), and it is possibly due to a shift away from maize to higher value crops that require more water per hectare per year. 
The average bulk water supply per planted area was $8655 \mathrm{~m}^{3} / \mathrm{ha}$, which is the gross irrigation demand. This value has decreased the last two years, and would have done so for the last three years if the ORWUA hadn't experienced water shortages during the 2003/2004 season due to large planted areas and limited canal capacity. This would possibly have increased the volume of water supplied during that season.

The ratio between the average net and gross values is 0.757 , which means that on average $24.3 \%$ of the water abstracted at the Scheiding Pumping Station can be allocated to operational losses such as evaporation, seepage, spills, etc. The ratio has been increasing over the last three years (from 0.74 to 0.78 ) indicating that water use efficiency at scheme level has improved and operational losses have been reduced.

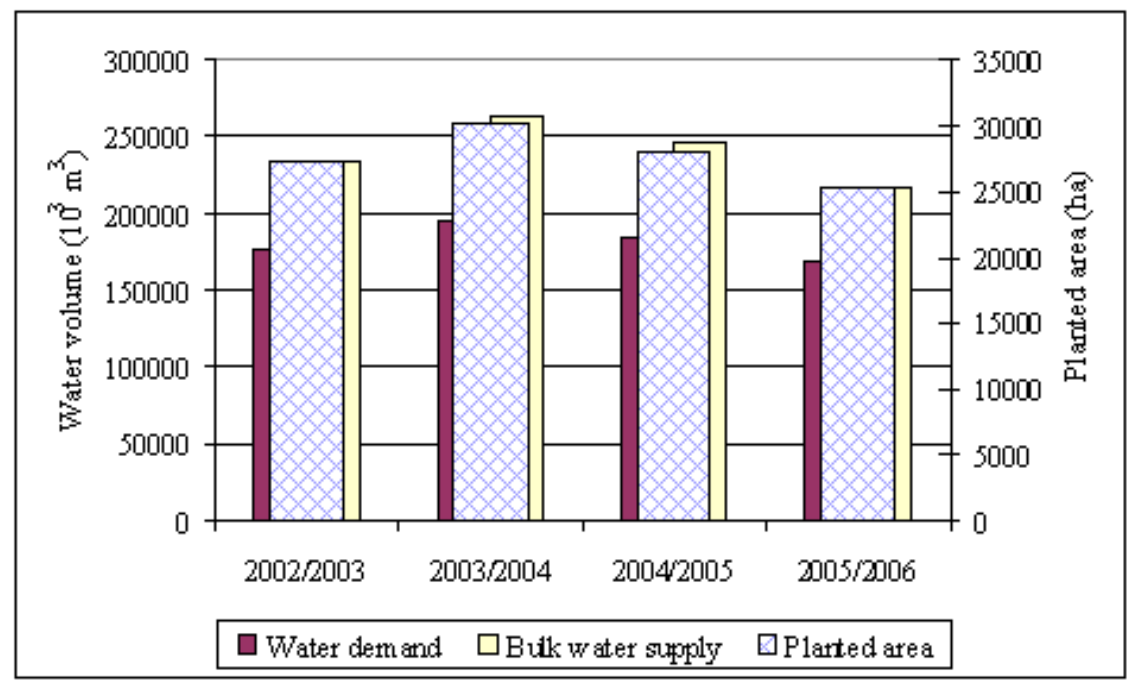

Figure 6: Water supply and demand at the ORWUA (2002 to 2006).

\section{Conclusion}

The crop water use module that has been developed for the WAS program has proved to be a useful and simple tool for recordkeeping, water management planning and benchmarking.

It is used by the ORWUA to plan pumping rates for the main water supply to the scheme, and to assess water availability according to the farmers' planting programmes. The results of four years' data collection and analysis at the ORWUA have shown that:

- There has been a decline in planted areas in the scheme during the last four water years;

- The net irrigation demand per planted area has increased during the last three water years, probably due to a shift in crop selection; 
- The gross irrigation demand per planted area have decreased over the past three water years, probably due to an improvement in water management and

- The ratio of net to gross irrigation demand per planted area has remained almost constant over the four years at 0.747 with no significant upward or downward trends.

The program has been very effective to evaluate the available data but the following recommendations for improvement can be made:

- A data export function should be added so that results can be exported to a spreadsheet program for further analysis; and

- The "sort by user" function should be changed so that multiple individual users can be randomly selected.

The researchers would like to thank the staff of Orange-Riet Water User Association for their assistance in collecting and capturing the data, and making it available for use in this paper.

\section{References}

[1] Department of Water Affairs and Forestry (DWAF). National Water Act No. 36 of 1998. Government Gazette No. 19182, South Africa, August 1998, www.gov.za.

[2] Department of Water Affairs and Forestry (DWAF). Implementation Guidelines for Water Conservation and Water Demand Management in Agriculture. Directorate WCDM, Pretoria, South Africa, www.dwaf.gov.za.

[3] Benadé, N., Annandale, J. and Van Zijl, H., The Development of a computerized Management system for Irrigation Schemes Water Research Project Report No. 513/1/97, Water Research Commission of South Africa, Pretoria, 1997.

[4] Crosby, C.T. \& Crosby, C.P., SAPWAT: A computer programme for establishing irrigation requirements and scheduling strategies in South Africa, Water Research Commission of South Africa, Pretoria, 1999. 